\title{
How dysfunctional are the dysfunctional attitudes in another culture?
}

\author{
Nesrin H. Şahin* \\ Psycbological Counselling and Research Centre, Bilkent University, 06533 Ankara, Türkiye \\ Nail Şahin* \\ Middle East Technical University Ankara, Türkiye
}

\begin{abstract}
The Dysfunctional Attitude Scale (DAS-A) has been used in many studies to measure depressogenic attitudes, vulnerability to depression and to assess the effectiveness of cognitive therapy. Despite its frequent use in research, no data have yet been reported on its item validity. The purpose of the present study was to investigate the item validity and psychometric properties of the DAS-A in the Turkish cultural context. The subjects were 345 university students. The locally adapted versions of the Beck Depression Inventory and the Automatic Thoughts Questionnaire were also administered. The reliability coefficients and the factor structure of the DAS-A were found to be similar to those reported in the West. However, the total mean was found to be unusually high. The reason for this elevated mean score was found to reside in the response patterns of the subjects to the reverse items. None of these 10 reverse items discriminated the dysphoric and non-dysphoric groups. A closer examination revealed these 10 items to reflect autonomous attitudes. It seems that these 10 reverse items do nothing but distort the mean scores and render cross-cultural comparisons difficult. Recent research on depression shows that, while autonomy may or may not be related to depression, sociotropy has consistent association with it. Researchers in other cultures and those working with minority and immigrant groups are warned against this bias inherent in the DAS-A.
\end{abstract}

Several studies on cognitive approach to depression have shown that the presence of negative life-events per se is not sufficient to induce this disorder. It seems that these negative events must also relate to and interact with a vulnerability factor which differs among individuals (Barnett \& Gotlib, 1988; Clark, Beck \& Stewart, 1989; Kuiper, Olinger \& Martin, 1988; Olinger, Kuiper \& Shaw, 1987).

Beck's cognitive theory of depression assumes that this predisposing vulnerability factor is related to dysfunctional attitudes or schemas (Beck, Rush, Shaw and Emery, 1979; Hammen, 1985). There is considerable research supporting this assumed relationship (Kuiper and Olinger, 1986; Norman, Miller \& Dow, 1988; Robins, Block \& Peselow, 1990; Wise \& Barnes, 1986).

\footnotetext{
* Requests for reprints.
} 
Outcome studies on cognitive therapy have also indicated that if the patients' dysfunctional attitudes are not simultaneously modified, the reduction in depressive symptoms may not be maintained. Therefore, the assessment of these core cognitive structures has both theoretical and practical implications (Beckham, 1990; Blackburn, Jones \& Lewin, 1986; DeRubeis \& Feeley, 1990 ; Peselow, Robins, Block, Barauche \& Fieve, 1990; Safran, 1990; Safran, Vallis, Segal \& Shaw, 1986; Simons, Murphy, Levine \& Wetzel, 1986).

Among the several assessment methods, the Dysfunctional Attitude Scale (DAS; Weissman \& Beck, 1978) is evaluated as the best predictor of subsequent symptomatic depression (Dobson \& Breiter, 1983; Dobson \& Shaw, 1986; Kuiper \& Olinger, 1986; Riskind, Beck \& Smucker, 1983; Rush, Weissenburger \& Eaves, 1986; Safran et al., 1986). The psychometric properties of the two versions (DAS-A, DAS-B) of this scale have been tested with clinical, adult and student populations. The scale has been used in many studies to measure depressogenic attitudes, vulnerability to depression and to assess the effectiveness of cognitive therapy.

Despite this frequent use of the DAS in studies which are based on the cognitive model of depression (Barnett \& Gotlib, 1990; Cottraux, Charles, Mollard \& Bouvard, 1989; Kauth \& Zettle, 1990; Zuroff, Igreja \& Mongrain, 1990), no data have yet been reported on its item validity. Psychometric evaluations of the scale take the instrument as a whole and analyse its reliability, validity and factor structure. However, a closer inspection of the validity of its individual items will undoubtedly contribute to our understanding of the scale's internal structure, as well as to improvement in its precision. Also it will enable cross-cultural replications which can contribute to our knowledge on the universality of the measured constructs.

The purpose of the present study is twofold. Firstly, DAS-A is analysed in terms of its item validity. Secondly, the psychometric properties of the instrument are checked in the Turkish cultural context. It was hypothesized that if the instrument measured the more stable, trait-like depressogenic schemata it was explicitly designed to measure, the psychometric properties in another culture should be similar.

\begin{abstract}
Method
Subjects

The subjects were 244 female and 101 male university students studying at the Aegean University in Izmir, Turkey. The age range of the subjects was 19-21. In terms of the SES level they were representative of the general population of university students in Turkey. The scales were administered to the subjects during a general required course.
\end{abstract}

\title{
Scales
}

1 The Dysfunctional Attitude Scale-Form $A(D A S-A)$ used in this study (Weissman \& Beck, 1978), is a self-report, seven-point Likert scale composed of items to assess typical, relatively stable depressogenic attitudes or assumptions indicative of typical self-schemas. It was designed initially as a 100 -item scale from which two parallel forms (40 items each) were developed. The possible range of scores in DAS$A$ is $40-280$. The internal consistency, test-retest reliabilities, average item-total correlations were studied with different samples and they were reported to be satisfactory. In studies which used student samples, the item-total correlations were reported to range between .20 and .50 ; the alpha's were between .87 and .92 ; the test-retest reliabilities were between .54 and .84 . Its correlations with the BDI 
ranged between .30 and .65; with the ATQ between .43 and .64 (Barnett \& Gotlib, 1988; Dobson \& Breiter, 1983; Dobson \& Shaw, 1986; Olinger et al. 1987; Riskind et al., 1983). The factor analytic studies of the DAS-A revealed four factors in a patient population (Parker, Bradshaw \& Blignault, 1984), two factors in a student population (Cane, Olinger, Gotlib \& Kuiper, 1986), and four factors in an unselected adult population (Oliver \& Baumgart, 1985).

The DAS-A is scored by adding the 40 items after reversing the items $2,6,12,17,24,29,30,35,37$ and 40 . These 'reverse items' were decided on an 'a priori' basis by Weissman \& Beck, and were assumed to reflect 'adaptive attitudes'. However, no empirical data on individual items are available (Weissman \& Beck, 1978). This scoring procedure continues to be used in many recent studies (See Barnett \& Gotlib, 1990; Cottraux, Charles, Mollard \& Bouvard, 1989; Kauth \& Zettle, 1990; Zuroff, Igreja \& Mongrain, 1990). The DAS-A was translated into Turkish by three independent psychologists with PhDs and was back-translated by three different instructors from the English Department. The translations were remarkably similar and a final Turkish DAS-A was developed with items the wording of which best matched the English form.

2 Beck Depression Inventory $(B D I)$ : This is a 21-item self-report inventory which measures the presence and severity of affective, cognitive, motivational, psychomotor and vegetative manifestations of depression (Beck, Ward, Mendelsohn, Mock \& Erbaugh, 1961). The score range is 0-63. The psychometric properties of the BDI are well known and it is probably the most widely used instrument in studies related to depression (Beck, Steer \& Garbin 1988). In a previous study, the first author adapted the 1978 version of the BDI into the Turkish culture and obtained information about its psychometric properties. The Turkish BDI was found to have good reliability (split-half is $r=.80$, Cronbach's alpha $=.74$ ). Its concurrent validities with the adapted Turkish version of the MMPI-D ranged between .63 and .50 on student and psychiatric samples, respectively (Hisli, 1988).

3 Automatic Thoughts Questionnaire (ATQ): This is a 30 -item, five-point Likert scale devised by Hollon \& Kendall (1980) which measures the frequency of occurrence of automatic negative selfstatements (thoughts) associated with depression. It has been found to significantly discriminate the dysphoric from the non-dysphoric criterion groups of college students. Scores range from 30 to 150 . The ATQ was previously adapted into the Turkish language by the authors and its local norms on university students were obtained. The adapted version, used in the present study has a split-half reliability of .91 , internal consistency of (Cronbach's alpha) .93 . Its correlation with the BDI was .75 (Şahin \& §̧ahin, in press).

\section{Procedure}

The three inventories were administered in a single session lasting approximately $25-35$ minutes. The order of administration was counterbalanced, half of the sample received the scales in the order DAS$\mathrm{A}, \mathrm{BDI}$ and ATQ, and the other half as ATQ, BDI and DAS-A.

\section{Results}

The data were analysed in several steps. First, the original scoring procedure proposed by Weissman \& Beck (1978) was followed and the reliability, validity and item statistics were obtained. Secondly, each DAS-A item was analysed individually to see whether it discriminated the dysphoric and non-dysphoric groups. Thirdly, the data were factor-analysed with four factors to compare the similarity of its structure with the original version.

\section{Results related to the original scoring procedure}

The split-half reliability (between odd and even numbered items) was found to be $r=.72$. The mean item-total correlation and the Cronbach's alpha were .34 and .79, 
respectively. These reliability figures are quite similar to those found in the literature. The correlation between DAS-A and the BDI was $r=.19(p \leqslant .001)$. The correlation with the ATQ was $r=.29(p \leqslant .001)$. These correlations are comparably lower than those reported with American samples. The correlation between the BDI and the ATQ was $r=.75(p \leqslant .001)$.

The mean of the sample on ATQ was $M=52.74$ (SD =14.87). The mean BDI score was $12.00(\mathrm{SD}=8.03)$. In different studies, means of similar magnitude were obtained on normal student populations in Turkey (Aytar, 1985; Hisli, 1989, 1990; Şahin \& Şahin, 1991; Şahin 1990; Şahin, Şahin \& Heppner, 1991). The total sample mean on DAS-A was 138.69 , with a standard deviation of 23.64. There were no statistically significant differences in terms of gender (females' mean $=137.95$, $\mathrm{SD}: 23.82$; males' mean $=140.47, \mathrm{SD}: 23.23$ ). It is worth noting here that a mean of comparable magnitude on DAS-A was reported only with depressed populations in the West $(M=138.73$; SD $=36.03)$ (Dobson \& Shaw, 1986). On the other hand, the highest mean that was reported on student populations was $M=125.55$ $(\mathrm{SD}=25.43$ ) (Wise \& Barnes, 1986). In general, the mean for normal populations is accepted as $M=117 \pm 26$ (Rush et al., 1986).

\section{Item validity analyses}

In order to check for the item validity of the DAS-A items, two groups were selected from the sample according to their BDI scores. Those who obtained a score of 9 and below on the BDI were classified as 'non-dysphoric' and those with scores 17 and above were classified as 'dysphoric'. The male/female ratios in these two groups were similar to the gender ratio in the total sample. There were 67 females and 28 males in the dysphoric group and 112 females and 43 males in the non-dysphoric group. The item scores were compared between the dysphoric and non-dysphoric groups, and the items that differentiated the two groups were identified. A total of 12 items (items: $3,4,7,8,9,10,15,16,20,26,28,31$ ) were found to meet this criterion (Table 1).

None of the 10 reverse items $(2,6,12,17,24,29,30,35,37,40)$, that Weissman \& Beck (1978) mentioned in their original work, discriminated the dysphoric and non-dysphoric groups. The procedure mentioned above for item validity was repeated with the ATQ cutting points (below 37 and above 68). Again, none of the 10 'reverse items' discriminated between the low and high ATQ groups. There was almost a complete overlap between the items which discriminated the low/high BDI or ATQ groups.

To rule out the possibility of extremity in responding which might appear in the $t$ test analyses, the responses on DAS-A items were dichotomized into 'I agree' and 'I don't agree' categories, excluding the neutral responses. A chi square value on the frequencies was computed for each item and those items that differentiated significantly between the non-dysphoric and dysphoric groups were identified. The results of the chi square analysis were identical to those of the $t$ test comparisons. Again, none of the 10 reverse items mentioned by Weissman \& Beck (1978) discriminated between the two groups. 
Table 1. Discriminative DAS-A items

\begin{tabular}{|c|c|c|c|}
\hline Item & $\begin{array}{l}\text { Non-dysphoric } \\
(N=155) \\
\text { BDI } \leqslant 9 \\
\text { Mean }\end{array}$ & $\begin{array}{l}\text { Dysphoric } \\
(N=95) \\
\text { BDI } \geqslant 17 \\
\text { Mean }\end{array}$ & $t$ \\
\hline $\begin{array}{l}\text { 3. People will probably think less } \\
\text { of me if I make a mistake }\end{array}$ & $3.33(1.71)$ & $4.25(1.67)$ & $4.18 * * *$ \\
\hline $\begin{array}{l}\text { 4. If I do not do as well as other } \\
\text { people all the time, people will not } \\
\text { respect me }\end{array}$ & $2.83(1.69)$ & $3.59(1.78)$ & $3.28 * * *$ \\
\hline $\begin{array}{l}\text { 7. I cannot be happy unless most } \\
\text { people I know admire me }\end{array}$ & $2.78(1.66)$ & $3.71(1.92)$ & $3.86 * * *$ \\
\hline $\begin{array}{l}\text { 8. If a person asks for help it is } \\
\text { a sign of weakness }\end{array}$ & $1.71(1.26)$ & $2.33(1.74)$ & $3.02 * *$ \\
\hline $\begin{array}{l}\text { 9. If I do not do as well as other } \\
\text { people, it means I am an inferior } \\
\text { human being }\end{array}$ & $2.22(1.56)$ & $3.30(1.93)$ & $4.60 * * *$ \\
\hline $\begin{array}{l}\text { 10. If I fail at my work then I am } \\
\text { a failure as a person }\end{array}$ & $2.10(1.62)$ & $2.93(1.87)$ & $3.51 * * *$ \\
\hline $\begin{array}{l}\text { 15. If other people know what you are } \\
\text { really like, they will think less of you }\end{array}$ & $2.65(1.78)$ & $3.27(1.95)$ & $2.48^{* *}$ \\
\hline $\begin{array}{l}\text { 16. I am nothing if a person I love } \\
\text { does not love me }\end{array}$ & $2.10(1.51)$ & $3.43(2.11)$ & $5.29 * * *$ \\
\hline $\begin{array}{l}\text { 20. If I don't set the highest standards } \\
\text { for myself, I am likely to end up a } \\
\text { second-rate person }\end{array}$ & $2.65(1.81)$ & $3.16(1.91)$ & $2.06 *$ \\
\hline $\begin{array}{l}\text { 26. If I ask a question it makes me } \\
\text { look inferior }\end{array}$ & $1.80(1.32)$ & $2.41(1.71)$ & $2.97 * *$ \\
\hline $\begin{array}{l}\text { 28. If you don't have other people to } \\
\text { lean on you are bound to be sad }\end{array}$ & $4.24(1.99)$ & $4.77(1.69)$ & $2.21 *$ \\
\hline $\begin{array}{l}\text { 31. I cannot trust other people because } \\
\text { they might be cruel to me }\end{array}$ & $3.09(1.81)$ & $3.57(1.87)$ & $2.02 *$ \\
\hline
\end{tabular}

$* * * p \leqslant .001 ; * * p \leqslant .01 ; * p \leqslant .05$.

Standard deviations are in parentheses.

\section{Factor analysis}

The data were subjected to principal components analysis with unities in the diagonal. Initially 14 factors were extracted with eigenvalues greater than one, explaining 59.3 per cent of the total variance. The scree test indicated that four factors would be appropriate for rotation. The varimax rotated factors were labelled as 'performance evaluation' (items: 1, 3, 4, 5, 7, 8, 9, 10, 11, 13, 14, 15, 16, 20, 26, 31, 33; 
subscale mean $M=47.55 ; \mathrm{SD}=14.58 ; \alpha=.81$ ), 'need for approval' (items : 19, 21, 22, $23,27,28,32,34,38,39,40$; subscale mean $M=50.62 ; \mathrm{SD}=10.53 ; \alpha=.74$ ), 'autonomous attitude' (items : $2,12,17,18,24,35$; subscale mean $M=20.21$, SD = $4.75 ; \alpha=.26$ ) and 'tentativeness' (items $6,29,30,36,37$; subscale mean $M=15.63$; $\mathrm{SD}=4.09 ; \alpha=.10)$. Only those items which had loadings greater than .30 were retained.

Four factor scale scores were developed by adding items of each factor. Computations with these subscale scores indicated that, subscale 1 (performance evaluation), and subscale 2 (need for approval), discriminated between the dysphoric/non-dysphoric and the low/high ATQ groups. However, subscale 3 (autonomous attitude), which in this study consisted entirely of the 'reverse items' proposed by Beck \& Weissman, failed to discriminate between these groups (Table 2).

Table 2. Extreme group comparisons on DAS-A factor scale scores

\begin{tabular}{|c|c|c|c|c|}
\hline Group & $\begin{array}{l}\text { Performance } \\
\text { evaluation } \\
\text { Mean }\end{array}$ & $\begin{array}{l}\text { Need for } \\
\text { approval } \\
\text { Mean }\end{array}$ & $\begin{array}{l}\text { Autonomous } \\
\text { attitude } \\
\text { Mean }\end{array}$ & $\begin{array}{c}\text { Tentativeness } \\
\text { Mean }\end{array}$ \\
\hline $\begin{array}{l}\text { Non-dysphoric } \\
\quad(B D I \leqslant 9, N=153) \\
\quad(B D I \text { mean }=5.29)\end{array}$ & $39.27(11.90)$ & $44.50(10.12)$ & $25.82(6.20)$ & $4.69(2.51)$ \\
\hline $\begin{array}{l}\text { Dysphoric } \\
\quad(\text { BDI } \geqslant 17, N=94) \\
\quad(\text { BDI mean }=22.81)\end{array}$ & $48.53(14.67)$ & $47.51(9.32)$ & $26.05(5.76)$ & $5.39(2.55)$ \\
\hline$t$ & $5.09 * * *$ & $2.36 * *$ & .30 n.s. & $2.10^{*}$ \\
\hline $\begin{array}{l}\text { Low ATQ } \\
\quad(\text { ATQ } \leqslant 37, N=32) \\
\quad(\text { BDI mean }=4.53)\end{array}$ & $34.41(11.33)$ & $41.94(12.14)$ & $26.19(7.88)$ & $4.69(2.42)$ \\
\hline $\begin{array}{l}\text { High ATQ } \\
\quad(\text { ATQ } \geqslant 68, N=46) \\
\quad(\text { BDI mean }=23.35)\end{array}$ & $51.15(16.12)$ & $48.98(10.51)$ & $26.30(5.76)$ & $5.13(2.71)$ \\
\hline$t$ & $5.39 * * *$ & $2.66 * *$ & .07 n.s. & $.76 \mathrm{n} . \mathrm{s}$ \\
\hline
\end{tabular}

$* * * p \leqslant .001 ; * * p \leqslant .01 ; * p \leqslant .05$.

Standard deviations in parentheses.

In addition, while the subscales 1 and 2 correlated significantly with the BDI and ATQ scores in the total sample (correlations ranged between .18-.33), subscales 3 and 4 did not correlate with these measures. In order to compare the factor structure with those reported in the literature, the data were forced to a two-factor solution. The resulting factor loading patterns were almost identical to Cane et al.'s findings (Cane et al., 1986), except that none of the reverse items appeared on the two factors of the present study.

Thus, in different statistical controls, the reverse items of the DAS-A, individually 
or as a cluster, emerge as devoid of any ability to discriminate between dysphoric/non-dysphoric groups and have no significant association with measures of automatic negative thoughts concomitant with depression.

\section{Discussion}

The results of this study are quite intriguing. When the DAS-A total score is considered, the psychometric properties of the Turkish version seem to be comparable to the original form. The reliability figures and the factor structure are similar, and the scale seems to discriminate the dysphoric and non-dysphoric university students. However, problems arise when the mean scores are compared with those reported in the literature. In the present study, unusually high mean scores were observed with the total sample as well as with the dysphoric and non-dysphoric groups. When one does not analyse any further, and takes these results at their face value, it can be concluded that Turkish university students have more dysfunctional attitudes compared to their peers in the West, and therefore are more vulnerable to depression. A closer look at the data, however, reveals that this conclusion is not warranted. Firstly, it should be noted that the same argument does not hold with the negative automatic thoughts. The mean score for the ATQ is comparable to the mean scores obtained with North American students. (Deardorff, McIntosh, Adamer, Bier \& Saalfeld, 1985; Dobson \& Breiter, 1983; Hollon \& Kendall, 1980). If negative automatic thoughts are considered as the 'surface level manifestations' of dysfunctional attitudes (Safran et al. 1986), one should be cautious in making the statement that Turkish university students have higher levels of dysfunctional attitudes.

Secondly, the results on the item validity analysis cast doubt on the validity of the DAS-A scores of our sample. The anomaly observed in the DAS-A mean score, can very well be due to the problem inherent in the so-called 'reverse items' of Weissman \& Beck. It should be emphasized here that none of the 10 items were verified empirically to be discriminative of the non-dysphoric and dysphoric groups. Instead, 12 different items were found to be discriminative in the present study.

The factor analysis provides additional evidence about the inadequacy of these reverse items. Among the four factor subscale scores, it was only the third subscale, called 'autonomous/individualistic attitudes', which failed to discriminate between the non-dysphoric and dysphoric groups $(\alpha=.26)$. Whereas the other two subscales, 'performance evaluation' (factor 1) and 'need for approval' (factor 2) had significant correlations with the BDI and the ATQ, and they significantly discriminated between the extreme groups defined by these two instruments.

It is possible that these autonomous items are endorsed by the sample as a matter of social desirability. Consider the following pairs of expressions (the italicised expressions are taken from the 10 original reverse items):

Happiness is more a matter of my attitude towards myself than the way other people feel about me. I cannot be happy unless most people I know admire me.

Making mistakes is fine because I can learn from them.

People will probably think less of me if I make a mistake. 
I don't need the approval of other people in order to be bappy.

I cannot be happy unless most people I know admire me.

The first expression in each pair reflects individualistic/autonomous attitudes focusing on the first person singular. However, the same content, with slight differences in wording (presented above as the second expression), becomes a sociotropic attitude. Semantically, the sociotropic statements are expressed in a more interpersonal perspective. They also seem to represent some type of a social anxiety and contingencies of self-worth. When worded in this fashion they do discriminate the non-dysphoric and dysphoric groups. It is possible that this type of wording brings these statements closer to the notion of self-schema as a self-worth contingency or a generalized representation of self-other relationships (Safran, 1990). It is also possible that, what really distinguishes the non-dysphoric and dysphoric individuals is the representation of relationships between people, rather than descriptors of a selfevaluative nature which are found in the individualistic/autonomous 'reverse items' (Segal, 1988).

The supporting evidence for this view comes partly from research on sociotropy and autonomy. These studies showed that it was the dimension of sociotropy or socially defined self-worth which was associated with depression (Beck, Epstein, Harrison \& Emery, 1983; Gilbert \& Reynolds, 1990; Gilbert \& Trent, 1991; Pilon, 1989; Robins \& Block, 1988).

In conclusion, when Weissman \& Beck had selected their 10 'reverse items' for DAS-A, they did it on an a priori basis, assuming that agreement with these items would indicate more 'adaptive attitudes', therefore should lower the total score on the scale. Conversely, disagreement with these items would increase the total score. Two important points should be considered here; in a more sociotropic culture, where socially defined contingencies of self-worth are more important, individuals who would be inclined to disagree with these autonomous (reverse) items in the DAS-A, run the risk of being unjustly classified as 'vulnerable to depression'. This issue would become more acute in cross-cultural comparisons. For example, in the present study 27.3 per cent of our sample, regardless of being dysphoric or nondysphoric, disagreed with these 10 items, thereby elevating the sample mean. The second issue is that the validity of these 'adaptive' attitudes, which are assumed to make one 'less vulnerable' to depression, is already questionable in the West. Consequently, researchers working with subjects from different cultural backgrounds (minority groups, immigrants and lower SES subjects) should be alert to this bias inherent in the DAS-A. Until appropriate revisions are made, the results of this scale should be interpreted with due caution. This revision should also take into consideration the need for cross-cultural replications to establish the universality of the constructs under investigation.

\section{References}

Aytar, G. (1985). Bir grup üniversite öğrencisinde yaşam olayları, depresyon ve kaygı araştırması (A study of life-events, depression and anxiety on a group of university students). XXI. Ulusal Psikiyatri ve Nörolojik Bilimler Kongresi, Çukurova Úniversitesi.

Barnett, P. A. \& Gotlib, I. H. (1988). Dysfunctional attitudes and psychosocial stress: The differential prediction of future psychological symptomatology. Motivation and Emotion, 12 (3), 251-270. 
Barnett, P. A. \& Gotlib, I. H. (1990). Cognitive vulnerability to depressive symptoms among men and women. Cognitive Therapy and Research, 14 (1), 47-61.

Beck, A. T., Epstein, N., Harrison, R. P. \& Emery, G. (1983). Development of the Sociotropy Autonomy Scale: A measure of personality factors in depression. Unpublished manuscript. University of Pennsylvania, Philadelphia.

Beck, A. T., Rush, A. J., Shaw, B. F. \& Emery, G. (1979). Cognitive Therapy of Depression. New York: Guilford Press.

Beck, A. T., Steer, R. A. \& Garbin, M. G. (1988). Psychometric properties of the Beck Depression Inventory: Twenty-five years of evaluation. Clinical Psychology Review, 8, 77-100.

Beck, A. T., Ward, C. H., Mendelsohn, M. J. \& Erbaugh, J. (1961). An inventory for measuring depression. Archives of General Psychiatry, 4, 561-571.

Beckham, E. E. (1990). Psychotherapy of depression research at a crossroads: Directions for the 1990s. Clinical Psychology Review, 10, 207-228.

Blackburn, I. M., Jones, S. \& Lewin, R. J. P. (1986). Cognitive style in depression. British Journal of Clinical Psychology, 25, 241-251.

Cane, D. B., Olinger, L. J., Gotlib, I. H. \& Kuiper, N. A. (1986). Factor structure of the Dysfunctional Attitude Scale in a student population. Journal of Clinical Psychology, 42 (2), 307-308.

Clark, D. A., Beck, A. T. \& Stewart, B. (1989). Sociotropy and autonomy: Cognitive vulnerability markers or symptom variables? Paper presented at the World Congress of Cognitive Therapy, 28 June-2 July, Oxford.

Cottraux, J., Charles, S., Mollard, E. \& Bouvard, M. (1989). Validation study of the French version of the Dysfunctional Attitude Scale (Form-A). Paper presented at the World Congress of Cognitive Therapy, 28 June 2 July, Oxford.

Deardorf, P. A., McIntosh, A., Adamer, A., Bier, M. \& Saalfeld, S. (1985). Automatic Thoughts Questionnaire: A study of concurrent validity. Psychological Reports, 57, 831-834.

DeRubeis, R. J. \& Feeley, M. (1990). Determinants of change in cognitive therapy for depression. Cognitive Therapy and Research, 14 (5), 465-482.

Dobson, K. S. \& Breiter, N. J. (1983). Cognitive assessment of depression: Reliability and validity of three measures. Journal of Abnormal Psychology 92 (1), 31-40.

Dobson, K. S. \& Shaw, B. F. (1986). Cognitive assessment with major depressive disorder. Cognitive Therapy and Research, 10 (1), 13-29.

Gilbert, P. \& Reynolds, S. (1990). The relationship between the Eysenck personality questionnaire and Beck's concept of sociotropy and autonomy. British Journal of Psychology, 29, 319-325.

Gilbert, P. \& Trent, D. (1991). Depression in relation to submission and other rank-related attributes. Manuscript submitted for publication.

Hammen, C. (1985). Predicting depression: A cognitive-behavioral perspective. In P. C. Kendall (Ed.), Advances in Cognitive-Behavioral Research and Therapy, vol. 5, pp. 30-71. New York: Academic Press.

Hisli, N. (1988). Beck Depresyon Envanteri'nin psikiyatri hastaları için geçerliği. (A study on the validation of the BDI: Turkish sample of psychiatric outpatients). Psikoloji Dergisi, 21, 118-126.

Hisli, N. (1989). Beck Depresyon Envanteri'nin üniversite öğrencileri için geçerliği ve güvenirliği (Reliability and validity of the Beck Depression Inventory for university students). Psikoloji Dergisi, 23, 3-13.

Hisli, N. (1990). Dönüş yapan ikinci kuşakta uyum yapabilenler ve yapamayanların otomatik düşünceleri, fonksiyonel olmayan tutumları ve problem çözme yeterliliği konusunda kendilerini algılayışları (Automatic thoughts, dysfunctional attitudes and perceived problem solving skills of the second generation Turkish migrants). Seminer Dergisi, 8, 711-723.

Hollon, S. D. \& Kendall, P. C. (1980). Cognitive self-statements in depression: Development of an Automatic Thoughts Questionnaire. Cognitive Therapy and Research, 3, 383-396.

Kauth, M. R. \& Zettle, R. D. (1990). Validation of depression measures in adolescent populations. Journal of Clinical Psychology, 46 (3), 291-295.

Kuiper, N. A. \& Olinger, L. J. (1986). Dysfunctional attitudes and a self-worth contingency model of depression. In P. C. Kendall (Ed.), Advances in Cognitive-Behavioral Research and Therapy, vol. 5, pp. 116-142. New York: Academic Press.

Kuiper, N. A., Olinger, L. J. \& Martin, R. A. (1988). Dysfunctional attitudes, stress, and negative emotions. Cognitive Therapy and Research, 12 (6), 533-547. 
Norman, W. H., Miller, I. W. \& Dow, M. G. (1988). Characteristics of depressed patients with elevated levels of dysfunctional cognitions. Cognitive Therapy and Research, 12 (1), 39-52.

Olinger, L. J., Kuiper, N. A. \& Shaw, B. F. (1987). Dysfunctional attitudes and stressful life events: An interactive model of depression. Cognitive Therapy and Research, 11 (1), 25-40.

Oliver, J. M. \& Baumgart, E. P. (1985). The Dysfunctional Attitude Scale: Psychometric properties in an unselected adult population. Cognitive Therapy and Research, 9, 161-167.

Parker, A., Bradshaw, G. \& Blignault, I. (1984). Dysfunctional attitudes: Measurement, significant constructs and links with depression. Acta Psycbiatrica Scandinavica, 70, 90-96.

Peselow, E. D., Robins, C., Block, P., Barauche, F. \& Fieve, R. R. (1990). Dysfunctional attitudes in depressed patients before and after clinical treatment and in normal control subjects. American Journal of Psychiatry, 147 (4), 439-444.

Pilon, D. J. (1989). The Sociotropy-Autonomy Scale in a university population: An overview. Paper presented at the World Congress of Cognitive Therapy, 28 June-2 July, Oxford.

Riskind, J.H., Beck, A. T. \& Smucker, M. R. (1983). Psychometric properties of the Dysfunctional Attitude Scale in a clinical population. Paper presented at The World Congress on Behavior Therapy, Washington, DC.

Robins, C. J. \& Block, P. (1988). Personal vulnerability, life events and depressive symptoms: A test of a specific interactional model. Journal of Personality and Social Psychology, 54, 846-852.

Robins, C. J., Block, P. \& Peselow, E. D. (1990). Endogenous and non-endogenous depressions: Relations to life events, dysfunctional attitudes and event petceptions. British Journal of Clinical Psycbology, 29, 201-207.

Rush, A. J., Weissenburger, J. \& Eaves, G. (1986). Do thinking patterns predict depressive symptoms? Cognitive Therapy and Research, 10 (2), 225-236.

Safran, J. D. (1990). Towards a refinement of cognitive therapy in light of interpersonal theory: I. Theory. Clinical Psychology Review, 10, 87-105.

Safran, J. D., Vallis, M. T., Segal, Z. V. \& Shaw, B. F. (1986). Assessment of cognitive processes in cognitive therapy. Cognitive Therapy and Research, 10 (3), 509-526.

Sahin, N. H. (1990). Re-entry and the academic and psychological problems of the second generation. Psycbology in Developing Societies, 2 (2), 165-182.

Şahin, N. (1991). Self-image among Turkish adolescents. Paper presented at the IACCP Debrecen Conference, Debrecen, Hungary.

Şahin, N. \& Şahin, N. H. (1991). Adolescent concerns: A comparison of adolescents in a cross-cultural perspective. Paper presented at the IACCP Debrecen Conference, Debrecen, Hungary.

Şahin, N. H. \& Şahin, N. (in press). Reliability and validity of the Turkish version of the Automatic Thoughts Questionnaire. Journal of Clinical Psychology.

Şahin, N., Şahin, N. H. \& Heppner, P. P. (1991). The psychometric properties of the Problem Solving Inventory (PSI) in a group of Turkish university students. Manuscript submitted for publication.

Segal, Z. V. (1988). Appraisal of self-schema construct in cognitive models of depression. Psychological Bulletin, 103 (2), 147-162.

Simons, A., Murphy, G. E., Levine, J. \& Wetzel, R. (1986). Cognitive therapy and pharmacotherapy for depression. Arcbives of General Psycbiatry, 43, 43-48.

Weissman, A. N. \& Beck, A. T. (1978). Development and validation of the Dysfunctional Attitude Scale: A preliminary investigation. Paper presented at the Annual Meeting of The American Educational Research Association, Toronto, Ontario.

Wise, E. H. \& Barnes, D. R. (1986). The relationship among life events, dysfunctional attitudes and depression. Cognitive Therapy and Research, 10 (2), 257-266.

Zuroff, D. C., Igreja, I. \& Mongrain, M. (1990). Dysfunctional attitudes, dependency, and self-criticism as predictors of depressive mood states: A 12-month longitudinal study. Cognitive Therapy and Research, 14 (3), 315-326.

Received 24 April 1991; revised version received 17 July 1991 